\title{
Technique
}

\section{A method for rapid placing of small intestinal perfusion tubes}

MILTON G. SCHMITT, JR ${ }^{1}$, CAROL M. WOOD, AND KONRAD H. SOERGEL From the Department of Gastroenterology, Medical College of Wisconsin, Milwaukee County General Hospital, Milwaukee, Wisconsin, USA

Small intestinal perfusion for studying intestinal absorption in man has been utilized for the past 12 years and has been adequately described (Whalen, Harris, Geenen, and Soergel, 1966; Fordtran, 1969). The technique requires a multilumen tube to be placed in the jejunum or ileum. A standard triplelumen perfusion tube is constructed of multiple polyvinyl tubes to which a rubber bag containing mercury is attached. The subject swallows the weighted rubber bag and gastrointestinal motor activity 'pulls' the bag and attached tube to the desired level of the small intestine. Using the present standard tube, the shortest time required for passage of a jejunal tube is one to three hours and an ileal tube three to 12 hours; progress frequently is especially slow in patients with intestinal diseases. In some instances, the tube does not pass the pylorus for a period of

Received for publication 15 January 1974.

${ }^{1} \mathrm{Dr}$ Schmitt is supported by a special postdoctoral research fellowship award (no. 5-FO3-AM-53883) from the National Institute of Arthritis, Metabolic and Digestive Diseases, National Institutes of Health, Bethesda, Maryland.

Please address correspondence to Dr Milton G. Schmitt, Jr, Milwaukee County General Hospital, 8700 West Wisconsin Avenue, Milwaukee, Wisconsin 53226, USA. four hours or more. A number of factors such as tube flexibility, anatomical variations, pylorospasm, and variable gastrointestinal motility make the time required for placing the tube highly variable. Intermittent fluoroscopy is used to locate the position of the tube and assist in navigation of the pylorus and duodenal sweep. The length of time required and degree of difficulty encountered in passing a tube causes a proportional increase in radiation exposure and thus decreases the number of studies a cooperative volunteer may perform.

Internal stiffening wires have been used to facilitate passage of Cantor tubes (Sargent and Meyers, 1969) and Crosby capsule biopsy tubes (Wicks and Clain, 1972). We have modified the standard triple-lumen perfusion tube to include a removable stiffening wire. The modified tube can be used for safe, reliable, and rapid insertion of small intestinal perfusion tubes.

\section{Tube Construction}

The modified triple lumen perfusion tube (fig 1 ) is constructed from the following components (see table).

\section{STIFFENING WIRE TUBE}

Four $\mathrm{cm}$ proximal to its end a $2.0 \mathrm{~mm}$ ID polyvinyl tube is heat. sealed for a distance of $5 \mathrm{~mm}$. The $4 \mathrm{~cm}$ tip is flexed upon itself so that the tip extends to the proximal edge of the heat seal and double tied with 2-0 surgical silk. Two rubber bags are prepared by cutting finger tips $(4 \mathrm{~cm})$ from a large Latex surgical glove. Both rubber bags are double-tied with 2-0

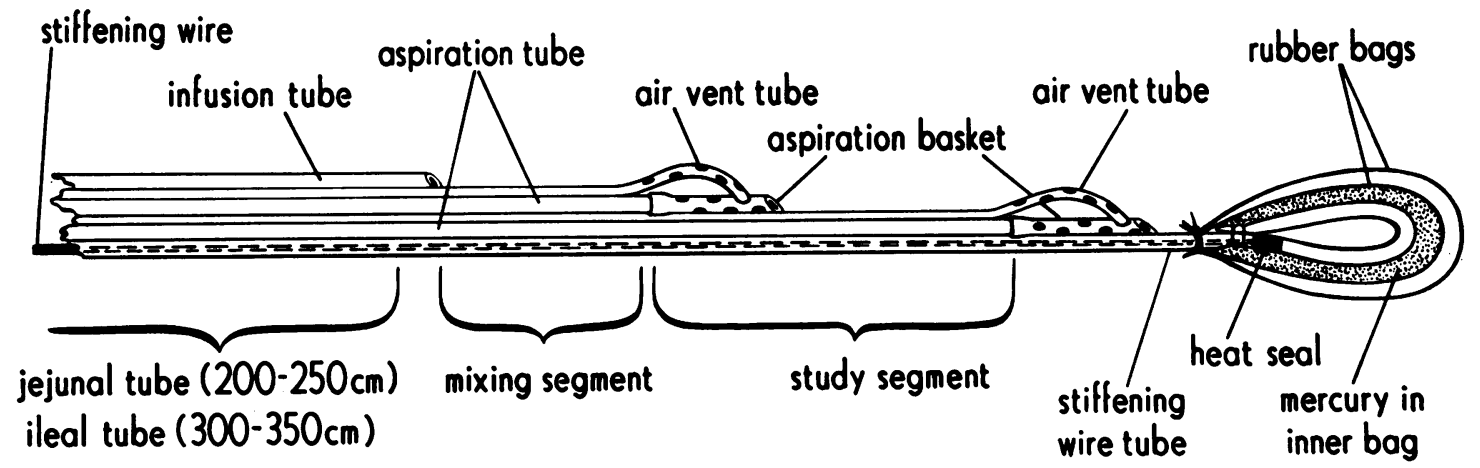

Fig 1 Schematic diagram of modified 'triple-lumen' perfusion tube. 


\begin{tabular}{|c|c|c|c|}
\hline Tube & Material & Size & Manufacturer \\
\hline Infusion tube & Radioopaque tubing & $1.6 \mathrm{~mm} \mathrm{ID}$ & $\begin{array}{l}\text { Ferraris Development \& Engineering Co Ltd, Edmonton, } \\
\text { London, England }\end{array}$ \\
\hline Aspiration tubes & Polyvinyl tubing & $1.6 \mathrm{~mm}$ ID & Pharmaseal Laboratories, Glendale, California 91201, USA \\
\hline Air vent tubes & Polyvinyl tubing & $1.2 \mathrm{~mm}$ ID & Pharmaseal Laboratories \\
\hline Stiffening wire tube & Polyvinyl tubing & $2.0 \mathrm{~mm}$ ID & Pharmaseal Laboratories \\
\hline Aspiration basket & Oxygen tubing & No. 10 French & C R Bard Inc, Murrey Hill, New Jersey 07974, USA \\
\hline Rubber bag & Latex surgical glove & Large & Massillon Rubber Co, Massillon, Ohio, USA \\
\hline
\end{tabular}

Table Materials for the modified triple-lumen perfusion tube

silk over the end of the tube so that the bags extend over the heat-sealed portion of the tube. Four puncture holes are made in the proximal portion of each bag with a 25 -gauge needle and the inner bag is filled with $0.5-1.0 \mathrm{ml}$ mercury.

\section{ASPIRATION TUBES}

A $1.6 \mathrm{~mm}$ ID polyvinyl tube is cemented with tetrahydrofuran to $2.5 \mathrm{~cm}$ of no. 10 French oxygen tubing in which four small holes have been cut on each side (aspiration basket).

\section{AIR VENT TUBES}

Five small holes are cut in the distal $2.5 \mathrm{~cm}$ of a $1.2 \mathrm{~mm}$ ID polyvinyl tube and cemented with tetrahydrofuran in a slight arc to the distal tip of the aspiration basket.

\section{INFUSION TUBE}

A $1.6 \mathrm{~mm}$ radioopaque tube is used unaltered.

The individual tubes are assembled into a circular bundle and cemented together over their entire length with tetrahydrofuran. The overall length is determined by the level of small intestine under study and the length of the mixing and study

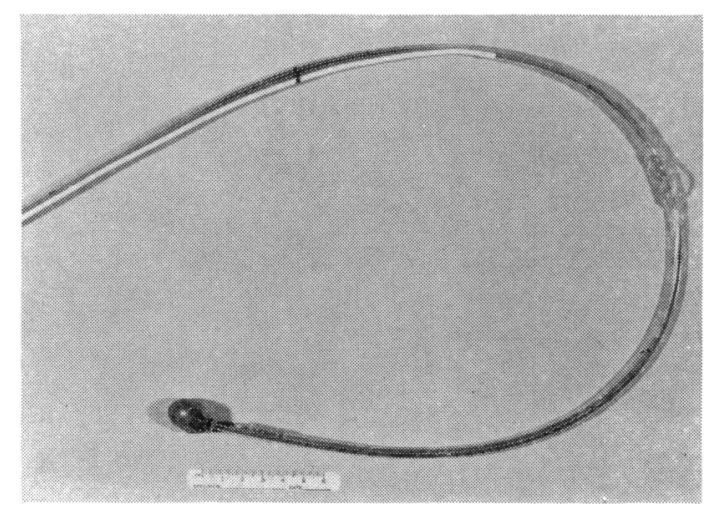

Fig 2 Modified triple-lumen perfusion tube. segments is determined by the type of perfusion study (fig 2).

\section{Method of Placing}

A $1.65 \mathrm{~mm}$ OD Teflon-coated, silicone-greased, stiffening wire is passed down the stiffening wire tube so that its distal tip is against the heat seal within the rubber bag. While sitting, the subject swallows the rubber bag. When the bag is in the body of the stomach $(50-55 \mathrm{~cm})$, the subject lies down on his right side and the entire tube is advanced progressively at the rate of $5-10 \mathrm{~cm}$ per minute. When the bag reaches the descending duodenum, the subject turns on his left side and the tube is advanced until the bag reaches the ligament of Treitz. The stiffening wire is then withdrawn $10 \mathrm{~cm}$ and the tube advanced $10 \mathrm{~cm}$. This step is repeated, passing the tube, but not the stiffening wire, over the ligament of Treitz until the tube is in the desired position in the small bowel. The radioopaque infusion tube is readily seen on fluoroscopy and allows correct placing for perfusion studies. When the tube is in place, the stiffening wire is completely withdrawn and the tube anchored at the mouth.

We have used this tube and method in 15 volunteer subjects. A jejunal tube is placed within 45 minutes, an ileal tube within one hour. Whereas fluoroscopy exposure ranged from two to five minutes with the conventional method, exposure is consistently less than two minutes with the new method. Acceptance of this procedure has been universal for no longer is there concern as to how long it will take to pass the tube.

\section{References}

Fordtran, J. S. (1969). Segmental perfusion techniques. Gastroenterology, 56, 987-989.

Sargent, E. N., and Meyers, H. I. (1969). Wire guide and technique for Cantor tube insertion (rapid small bowel intubation). Amer. J. Roentgenol., 107, 150-155.

Whalen, G. E., Harris, J. A., Geenen, J. E., and Soergel, K. H. (1966). Sodium and water absorption from the human small intestine: the accuracy of the perfusion method. Gastroenterology, 51, 975-984.

Wicks, T., and Clain, D. (1972). A guide wire for rapid jejunal biopsies with the Crosby capsule. Gut, 13, 571 . 